\title{
IMPLEMENTATION OF SMART SOLUTIONS IN THE INHOUSE LOGISTICS
}

\author{
Patrik Brigant ${ }^{1}$, Natália Horňáková ${ }^{1}$, Lukáš Jurík ${ }^{1}$, Dagmar Cagáňová1, Henrieta Hrablik \\ Chovanová $^{1}$, Marek Jemala ${ }^{1}$ \\ \{patrik.brigant@stuba.sk,natalia.hornakova@stuba.sk, lukas.jurik@stuba.sk\}
}

\author{
${ }^{1}$ Slovak University of Technology in Bratislava, Faculty of Materials Science and Technology in \\ Trnava, J. Bottu 25, 91724 Trnava
}

\begin{abstract}
The main aim of the presented paper is to propose the improvement of the handling process with the products in the warehouse by implementation of smart / intelligent solutions in the selected industrial enterprise in Slovakia. Based on the analysis of the current state in the selected enterprise and the assumed increase of the production identified by the enterprises, the proposal is to implement the automated guided vehicles from the sorting robots to the expedition zone. Automated guided vehicles are part of the Industry 4.0 concept, which is focused on increasing the competitiveness of industrial enterprises. The advantage of automated guided vehicles is that it can be used to transport and handle various materials such as pallets, small containers, boxes, etc.
\end{abstract}

Keywords: automation, AGV, smart solutions, industrial enterprise.

\section{Introduction}

Due to the constantly increasing competitive pressure, current trends in logistics are gradually being promoted in the conditions of the Slovak enterprises. From the point of view of the internal processes of the manufacturing enterprise, intra-company transport, which is focused on the transport of material / finished products inside the enterprise, plays an important role [1]. The use of advanced technology in the field of logistics provides space for improvement of business logistics processes and thus to secure competition for the company's logistics capability [2].

Intelligent / smart technology in industry and logistics is a relatively new concept that entered the market in the last few years. The impact of new trends on the logistics market in Slovakia is evident [2].

Enterprises are competing in the search for innovation in the logistics market, and thus technologies are developing at a dizzying pace [3].

Smart Connected System Logistics is formed by implementation of intelligent / smart technologies, ideas, and concepts into logistics processes. Smart Connected System Logistics is basically Intelligent Connected Products (e.g. Automated guided vehicles, automated storage equipment, etc.) organized through the cloud, while the cloud-based solution is also access to information from other data factory sources such as system planning and management, external logistics etc. [4].

Automated guided vehicles (AGVs) are fully automatic transport systems, electrically powered unmanned vehicles. AGVs safely transport all kinds of products without human intervention within production, logistic, warehouse and distribution environments. AGVs are primarily driven by computers, in some cases AGVs can also be manually controlled [5]. AGV 
vehicles can move parts and semi-products between workstations, into warehouses, inside the warehouses and from warehouses. However, careful planning, a refined handling system, and also a design solution of vehicles are required for their use [6].

The most common AGV navigation methods used are the following technologies $[6,7]$.

1. Guiding lines - color or magnetic lines, respectively tapes. The advantage of the mentioned lines is their easy removal from the floor, respectively change to another required course. Color or magnetic line technology is considered as passive because it does not need any source compared to the drivers. The advantage of color lines is the initial lower costs during the implementation, but maintenance costs can be incurred in terms of risk of dirt or damage, especially in large operations.

Magnetic tapes are more expensive and more reliable than color lines. On the surface of the store floor are glued or embedded $10 \mathrm{~mm}$ into the floor along the entire route. Magnetic tapes are made of ferrite magnetic dust, synthetic rubber and other materials. Sensing sensor that follows the magnetic field of the tape is placed on the trailer. The electronics monitor deviations from the marked path and send the signal to the control engine for vehicle direction correction. An obstacle sensor is also included. The obstacle sensor sends information about the necessary deceleration in case of obstacles and subsequent acceleration after their removal.

The scheme of guideline line technology is shown in Fig. 1

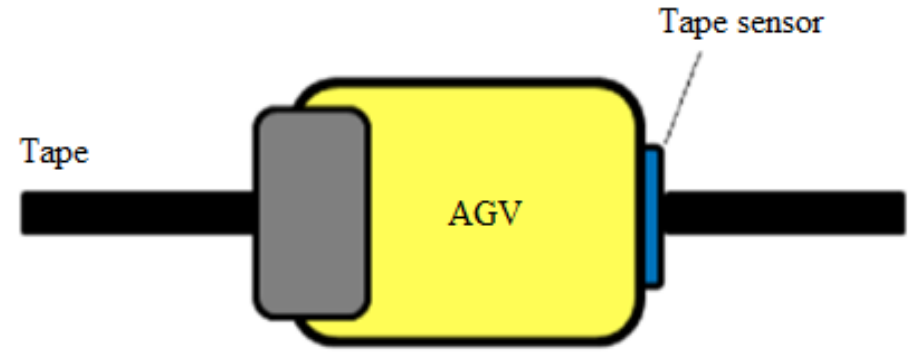

Fig. 1: The guidline line technology [8]

2. Network of magnetic points and gyroscope. AGV is navigated on the basis of gyro data. The processing of mentioned data determines the distance traveled and the change of trailer rotation. To increase accuracy and reliability, the network of magnets is placed into the floor. The position of magnets is also stored in the trailer's control system. Whenever the AGV passes through the magnetic point, the trailer is automatically calibrated. Magnetic point technology is more expensive than previous technology, as it is necessary to modify the floor (drilling the holes and embedding magnetic points). The technology of magnetic point and gyroscope technology is shown in Fig. 2. 


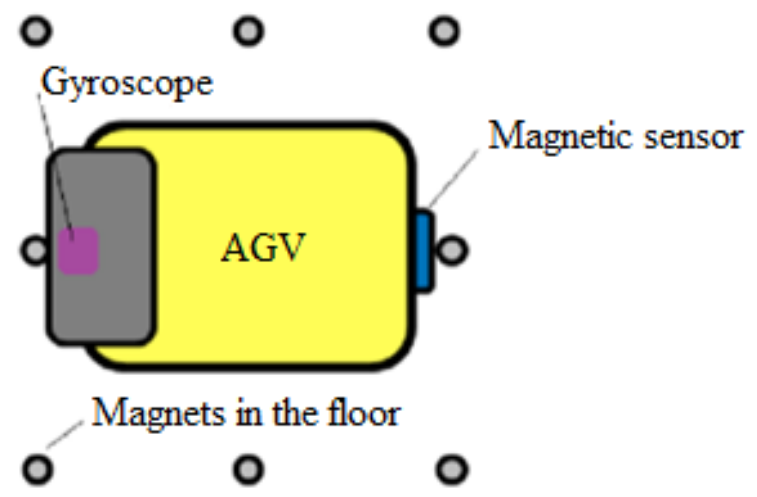

Fig. 2: The technology of magnetic point and gyroscope technology [8]

3. Camera guidance technology - attachment of one or more cameras to the trailer. The route is created by manually navigated trailer. Attached cameras scan the surroundings at an angle of 360 degrees. Subsequently, the trailer automatically follows the mapped route. The scheme of camera guidance technology is shown in Fig. 3

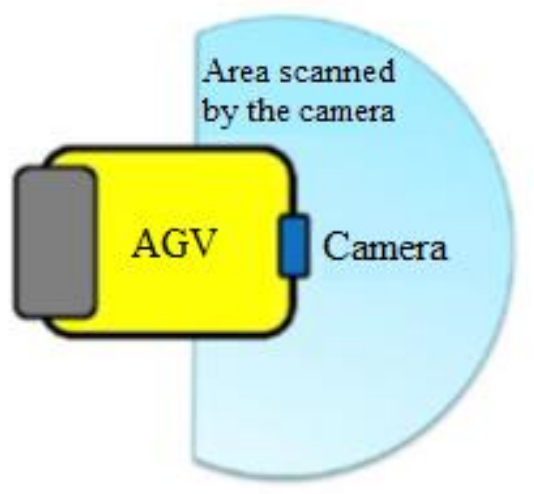

Fig. 3: Camera guidance technology [8]

4. Laser guidance technology. In wireless laser navigation, retroreflective materials (such as tapes or mirrors) are placed on pillars, walls or other devices. The AGV has a rotating tower with a laser transmitter and receiver capable of transmitting and receiving laser rays at a certain angle. Using the control system, the distance and subsequently the route are automatically calculated and stored in the AGV memory. System navigates the AGV to the certain destination by continually updating the location.

\section{The analysis of the current state of the product handling process in the warehouse in the selected enterprise}

The analysis of the current state of the product handling was carried out in an industrial enterprise in Slovakia which deals with the production of tires.

At present, the transport / handling of the final products in the company is realized by forklifts. The enterprise disposes of the following types of forklifts: 
- forklifts with clamp attachment, which are used in handling with CVT (type of truck tire) and

- forklifts used for handling with specialized metal column pallet (KSP) in width and lenght.

In the Sorting and Palletizing ( $\mathrm{S} \& \mathrm{P})$ process, the products are handled in two ways:

1. Tires are transported to the warehouse by KSP and forklifts and subsequently stored.

2. Tires are moved to the rail ramp in the form of chimneys by using trailers and industrial trucks.

In the first method, during the S\&P process, the operator of frontal forklift loads an empty KSP on the roller track. After S\&P process, the robot loads the products on a pre-prepared KSP. Subsequently, the operator removes the full KSP and moves it to the location where the data are uploaded to the Warehouse Management System (WMS). The operator read the product bar code of the given dimension and read the KSP bar code to make it possible to pair a particular type of tire with the given KSP. The operator counts the number of pieces and adds to the WMS that generates the storage position.

After uploading the data to the WMS, the operator moves the KSP into the expedition zone on a freight ramp using a forklift. Subsequently, the KSP is loaded and transported by shuttle service to a newly-built warehouse in the west of Slovakia.

In the second method, automated sorting robots for CVT stacked tires into homogeneous chimneys of the same type and size load onto a manual roller conveyor. The operator with the forklift with special clamp attachment removes the stacked tires from conveyor and upload data to the WMS by scanning the tire bar code and counting the number of pieces of the same type of tire in the chimney. WMS generates a position on a rail ramp. The operator loads a stacked tire chimney on a non-powered truck that is secured by a tire grip. Loaded trucks are conveyed into the trailer, which increasing the use of a larger load capacity per carriage. Tires are transported to a rail ramp by using an industrial truck, where the tire are unloaded. Transport from automatic sorting robots to rail ramps is ensured by marked lines on the floor that are color-coded in an orange color. According to the lines, the operators are guided to ensure the security of manufactured tires during transport and handling. Finally, the tires are transformed into higher chimneys and are ready for loading into railway wagons or megaboxes.

The storage facilities of the enterprise were located in three cities in Slovakia (by the end of the 2016) marked as warehouse A, warehouse B - $20 \mathrm{~km}$ from the enterprise and warehouse $\mathrm{C}-46 \mathrm{~km}$ from the enterprise. The main warehouse (warehouse A) is part of the enterprise where all passenger and light truck tires (PLTs) are stored first features and part of PLT spare consumption. First and secondary consumption CVT were stored in warehouse A by the end of 2016.

Other tires are stored in the expedition warehouse (warehouse B) and the rest of tires were stored in the non-expedition warehouse (warehouse C) by the end of 2016. At present, the warehouse A is unconsolidated due to the overfilling of storage capacities. The evidence is storing of tires in place reserved for storing empty KSPs. As the enterprise assumed / assume increased demand for its products in the future, the management decided to build own expedition warehouse in the west of Slovakia (26 km from the main warehouse), which will store exclusively CVT. The storage process started in 2017.

According to the constant increase in production volume and the planned expansion of production, it is necessary to ensure optimization and improvement of selected internal company logistics system processes in the enterprise. 


\section{The implementation of intelligent solutions in the storage process in the selected enterprise}

The proposal is to implement a fully automated, efficient and economical AGV - Compact GG (Fig. 4) for KSP transport with counterbalance, optimized and equipped for quick and easy commissioning. AGV - Compact GG is capable independently working during four shifts, i.e. 24 hours via microprocessor and managing supervisor. For the selected enterprise, the warehouse, is suitable due to its radius of rotation, the small length and the chassis. Compact GG allows optimal handling during loading with the side feed and angle of fork.

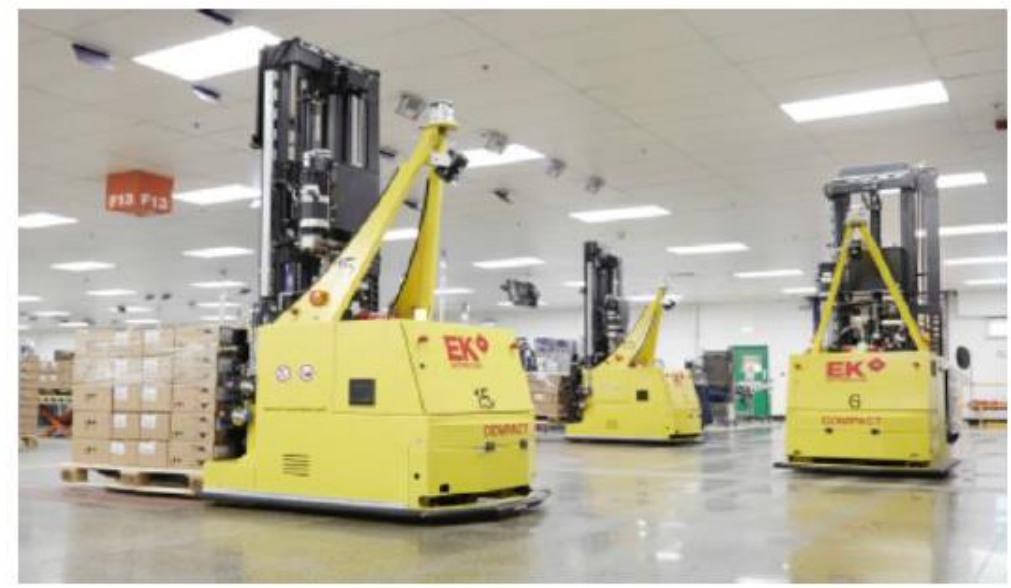

Fig 4: AGV - Compact GG [9]

The specific features of AGV - Compact GG were proposed for the needs of the selected enterprise. With respect and protection of enterprise sensitive data, the individual values were recalculated by the same coefficient.

- Chassis length: $1771 \mathrm{~mm}$

- Overal lenght: $3214 \mathrm{~mm}$

- Chassis width: $1127 \mathrm{~mm}$

- Max. width: $1282 \mathrm{~mm}$

- Chassis height: $1242 \mathrm{~mm}$

- Lift height: $32423 \mathrm{~mm}$

- Wheelbase: $1185 \mathrm{~mm}$

- $\quad$ Forward / Rewind Speed: max. 1,5 / 1,0 m/s

AGV - Compact GG will be guided by advanced intelligent software that will be integrated into every vehicle. A graphical user interface is part of a system that allows you to control an electronic device through the multiple interactive pixels that trigger commands. It takes approximately three weeks to put the management system into operation, followed by two-week monitoring for system analysis and optimization.

To implement the control system, it is necessary to ensure:

- PC server for AGV control system,

- standard visualization systems,

- software licenses,

- installation, 
- $\quad$ operating instructions and

- documentation.

The best solution for navigation is a combination of two technologies (Fig. 5).

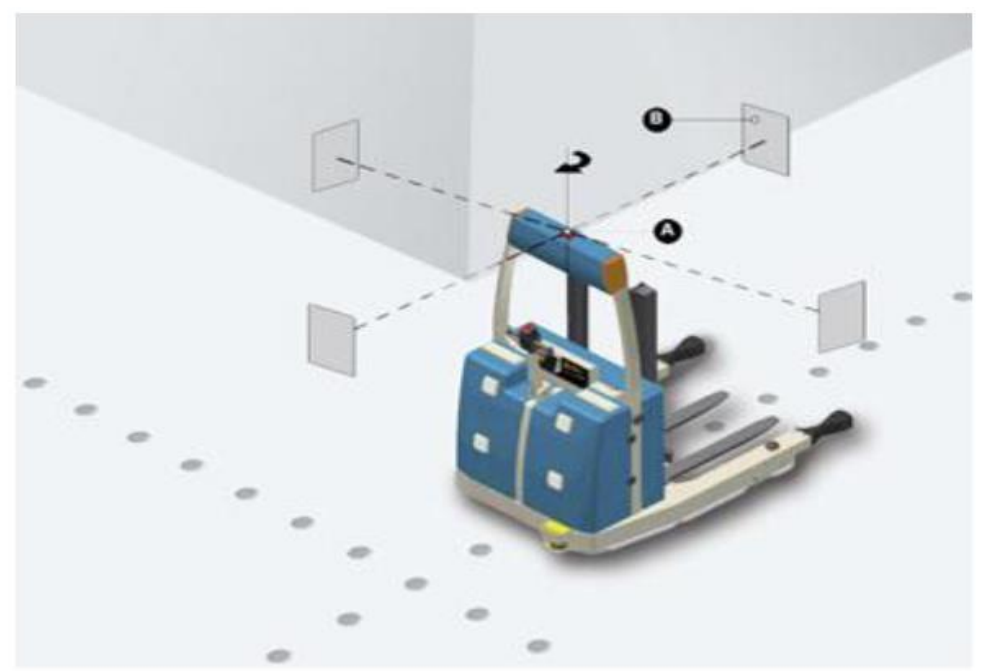

Fig 5: Combinated navigation for AGV [10]

The first technology is navigation using magnetic lines and points (distance between points is one meter), which will be implemented throughout the entire length of the route. There are six 90 degree corners along the route. The second technology is laser navigation. The AGV will be fitted with a rotating tower where the transmitter and receiver of the laser rays will be located. The technology will be used primarily for handling processes of KSP loading and unloading. The mirror will be implemented on the columns in process of KSP loading in the first position (the space for automated sorting robots for CVT), when loading the KSP. AGV can focus on the exact location of the KSP and load it by using mentioned mirrors.

The AGV - Compact GG will be connected with a battery that will power the wheels and ensure the positioning of the forklift by magnetic and laser navigation. The replacement of the battery will be ensured by the technology, named Battery Swap, i.e. manual battery replacement when electricity is exhausted, which requires the operator to manually remove the discharged battery and replace the battery with a fully charged battery while transporting the discharged battery to the recharging point. It takes about 5 to 10 minutes to replace the battery.

The route in the warehouse has a suitable floor without ascending or descending slopes and is of sufficient width, allowing the AGVs with the KSP to go smoothly along the route back and forth. The proposed route (Fig. 6) will begin with automated sorting robots by loading the KSP and then proceed to the expedition zone where the AGVs unload the KSP onto a hydraulic device designed for automation loading. There are three automatic doors along the route that will be connected to the AGV control system. In the event of a fire in a given section of the warehouse, the automatic door is closed, so it is necessary to set a time interval for the smooth exit of the AGVs. 


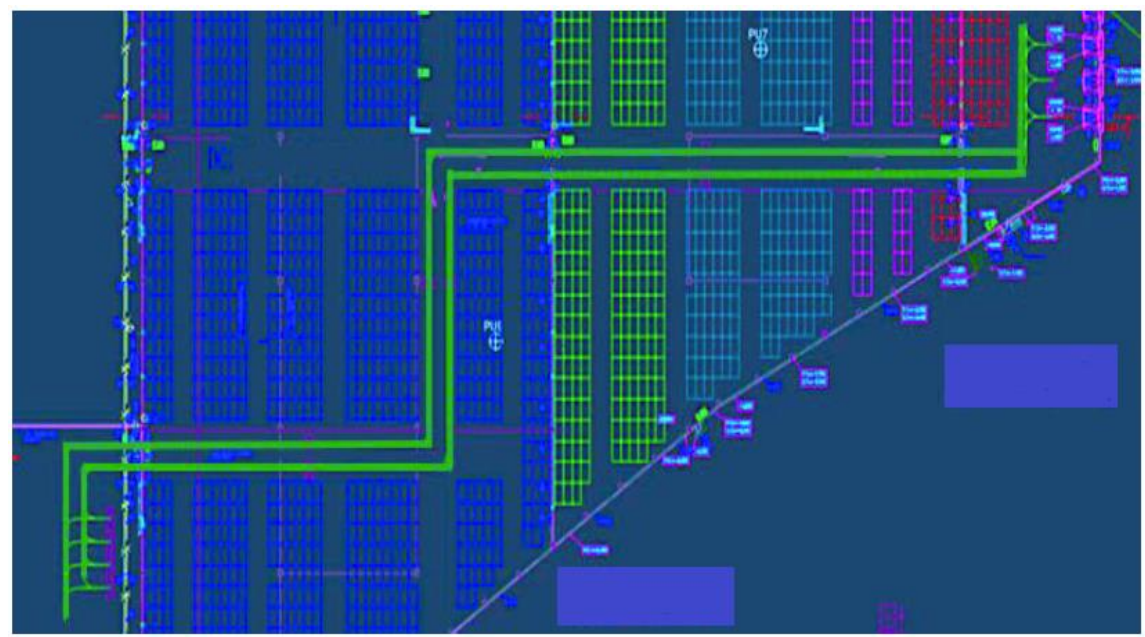

Fig 6: Route from the automated sorting robots to the expedition zone [8]

When calculating the total time of a circle, which represents 550 seconds, it is necessary to calculate the transport time from the automated sorting robots to the expedition zone, taking into account $10 \%$ of blocking and $2 \%$ of unavailability of the system. According to the mentioned, transport time will increase by $12 \%$, therefor the resulting transport value is 232 seconds.

Subsequentlly, the loading time of the full KSP from the automatic sorting robots is added to the transport time, and the time of unloading to the hydraulic device designed to load full KSPs is added to calculate the time (for transport, loading and unloading). The resulting value is 318 seconds.

When calculating the circle from loading full KSPs from automated sorting robots to unloading full KSPs on the first hydraulic device and then loading the empty KSPs from the second hydraulic device to returning to the automated sorting robot, it is necessary to calculate the transport time where is summed the lenght of the route from the automated sorting robots to the first hydraulic device with the length of the route from the first hydraulic device to the second one. As in the previous case, it is necessary to take into account $10 \%$ of blocking and $2 \%$ of unavailability of the system, what increasing transport time by $12 \%$, which means that the transport will take 250 seconds.

Subsequentlly, the loading time of the full KSP from the automatic sorting robots, the time of unloading to the first hydraulic device for loading the full KSP, the time of loading the empty KSP from the second hydraulic device, and the time of unloading the empty KSP in the automated sorting robots is added to the transport time, which present transport time, time for loading and unloading full KSPs and loading and unloading empty KSPs.

The total time of the circuit is generated by the sum of transport time with the transport, which means that the whole circuit takes 672 seconds.

To determine the number of AGVs, it is necessary to calculate how many pieces of KSP are produced annually, i.e., how many pieces need to be transported to the warehouse. Furthermore, it is necessary to divide the number of tires per KSP by the number that the AGV can take at once. Consequently, it is necessary to indicate how many pieces of KSP will be transported in one day. It is also necessary to determine how much KSP can be transported by AGV for one shift, while respecting the flexibility factor. 
Another calculation is how many KSPs will transport AGV for one shift. Based on the above mentioned calculations, the number of $\mathrm{AGVs}$ needed was 5, with the respect to the manual battery exchange factor.

\section{Conclusion}

The definition of logistics is widely used in transport, storage, converting materials into finished products and deliver them to an end users. Typically, logistics is seen as the actions of which the objective is to minimize costs and maximize profits [11]. Nowadays, logistics in industrial enterprises plays a key role and is one of the main enterprise expenditure items. The aim of logistics processes is to satisfy customer needs with the greatest flexibility, accuracy, reliability and economy. The authors of the article identified one of the trends in logistics the implementation of smart / intelligent solutions. The implementation of smart / intelligent solutions in logistics leads to time and costs savings.

The aim of the paper was to highlight the possibility of implementation smart / intelligent solutions in logistics specifically in inhouse transport and storage.

The following Table 1 summarizes the examples of strengths and weaknesses as well as opportunities and threats of AGV implementation in the selected industrial enterprise.

Table 1: Strenghts, weaknesses, opportunities and threats of AGV [8]

\begin{tabular}{|l|l|}
\hline \multicolumn{1}{|c|}{ Strenghts } & \multicolumn{1}{|c|}{ Weaknesses } \\
\hline Time and costs saving & Higher implementation investment \\
\hline $\begin{array}{l}\text { Process optimization } \\
\text { Running times reduction }\end{array}$ & Beed for more qualified personnel \\
\hline $\begin{array}{l}\text { Possibility of the work without break } \\
\text { Operation accuracy and safety }\end{array}$ & \\
\hline $\begin{array}{l}\text { Higher availability of the equipments } \\
\text { Traffic fluency }\end{array}$ & \\
\hline Safety of the traffic and operation & \\
\hline Opportunities & Electrical power failure \\
\hline $\begin{array}{l}\text { Compatible with other types of automation } \\
\text { potential production increasing }\end{array}$ & Rising of the electrical power price \\
\hline & \\
\hline
\end{tabular}

Based on a sumary of the strengths and weaknesses as well as the opportunities and threats of AGV implementation, it can be concluded that the implementetion of AGVs eliminates the negative findings resulting from the analysis of the current state of selected logistics processes in the enterprise. 
By the implementation of AGVs into practice, reductions of economic costs will be achieved and returns on investment related to the implementation of AGV is aproximately one and a half year.

Acknowledgments. This article is part of the KEGA project No. 030STU-4/2018 called "E-platform for Improving Collaboration among Universities and Industrial Enterprises in the Area of Education", VEGA project No. 1/0235/17 called "System identification of complex preconditions for supporting innovation and employment in the less developed regions of Slovakia", and Young Research Project No. 1321 called "Application of exact methods in decision-making processes in industrial enterprises conditions in Slovakia".

\section{References}

[1] Krajčovič, M. et. al.: Priemyselná logistika. Žilina: EDIS - vydavatel’stvo ŽU, Žilina 2014

[2] Stareček, A, Bachár, M., Horňáková, N. Cagáňová, D. Makyšová, H.: Trends in automatic logistic systems and logistic market in Slovakia. Vol. 5, iss. 1, pp. 7-14, Acta Logistica, SR 2018

[3] Witkowski, K.: The importance and effect of innovation and 4.0 Industrial Revolution on Logistics. Vol. 13, iss. 1, pp. 92-101. Fórum manažéra, Trnava 2017

[4] Gregor, T., Krajčovič, M., Więcek, D.: Smart Connected Logistics. Vol. 192, pp. 265-270. Procedia Engineering 2017

[5] Automatic Guided Vehicles (AGVs). DEMATIC. [2018-07-18]. Online: http://www.egemin-automation.com/en/automation/material-handling-automation_hasolutions/agv-systems

[6] Rushton, A., Oxley, J., Croucher, P.: The Handbook of Logistics and Distribution Management. 2nd edition. Kogan Page, London 2000

[7] Ullrich, G.: Fahrerlose Transportsysteme: Eine Fibel - mit Praxisanwendungen zur Technik - für die Planung. Springer Fachmedien Wiesbaden GmbH, 2011

[8] Brigant, P.: Návrh na zefektívnenie vybraných procesov podnikového logistického systému podniku Continental Matador Rubber, s.r.o. [Diplomová práca] - Slovenská technická univerzita v Bratislava. Materiálovotechnologická fakulta so sídlom v Trnave; Ústav priemyselného inžinierstva a manažmentu. MTF STU, Trnava 2017

[9] Transport Robotics Intralogistics Simulation. EK Automation. [2018-07-20]. Online: https://ek-automation.com/en/agvs/

[10] Guidance systems. System logistics. [2018-07-20]. Online: http://www.systemlogistics.com/eng/products/agv-automated-guided-vehicles1/guidance-systems, 2017

[11] Bajdor P.: Comparison between sustainable development concept and green logistics. The Literature review in Polish journal of management studies. Vol. 5., Częstochowska 2012 